\title{
Socio-demographic Predictors of Perceived Health among Syrian Refugees in Jordan
}

\author{
Hamza Alduraidi ${ }^{1}$, Zyad Saleh ${ }^{2}$, Ayman Hamdan-Mansour ${ }^{3}$
}

${ }^{1} R N$, MPH, PhD. Director, Accreditation Department, Accreditation and Quality Assurance Center; Assistant Professor, Community Health Nursing Department, School of Nursing, The University of Jordan, Amman, 11942, Jordan, ${ }^{2} R N$, PhD. Associate Professor, Clinical Nursing Department, School of Nursing, The University of Jordan, Amman, 11942, Jordan, ${ }^{3}$ Professor, Community Health Nursing Department, School of Nursing, The University of Jordan, Amman, 11942, Jordan

\begin{abstract}
The purpose of this study is to investigate the association between socio-demographic characteristics and perceived health among Syrian refugees in Jordan.

Method: A cross-sectional quantitative descriptive design was adopted, where a sample of 151 Syrian refugees living inside and outside camps in Amman,Jordan was surveyed for physical, psychological, social and environmental perceived health using a 12-item questionnaire.

Results: Each domain's score was computed out of 60 . The mean perceived physical health was $27.6 \pm 11.5$; perceived psychological health 27.1 \pm 10.1 ; perceived social health $32.6 \pm 10.3$; and perceived environmental health $30 \pm 9.1$. Predictors of perceived physical health included age group $\mathrm{F}_{(2)}=3.12, \mathrm{p}=.012$, marital status $\mathrm{F}_{(3)}=4.71, \mathrm{p}=.004$, and income level $\mathrm{F}_{(2)}=1.75, \mathrm{p}=.047$. Predictors of perceived psychological health included income level $\mathrm{F}_{(2)}=2.79, \mathrm{p}=.005$, place of living $\mathrm{t}=3.32, \mathrm{p}=.007$, and marital status $\mathrm{F}_{(3)}$ $=4.09, \mathrm{p}=.034$. Predictors of perceived social health included gender $\mathrm{t}=2.04, \mathrm{p}=.026$, age group $\mathrm{F}_{(2)}=$ $3.64, \mathrm{p}=.000$, living place $\mathrm{t}=-3.61, \mathrm{p}=.031$, and household size $\mathrm{r}=.61, \mathrm{p}=.048$. And the only predictor of perceived environmental health included was place of living $t=5.64, p=.000$.

Conclusion: Living inside refugee camp, large household, poverty, older age, and being divorced or widow are associated with lower perceived health. Modifying some factors may help improve perceived health among Syrian refugees in Jordan and beyond.
\end{abstract}

Keywords: Perceived health, Socio-demographic predictors, Syrian refugees.

\section{Introduction}

\section{Correspondence Author:}

\section{Hamza Alduraidi, RN, MPH, PhD}

Director, Accreditation Department, Accreditation and Quality Assurance Center; Assistant Professor, Community Health Nursing Department, School of Nursing, The University of Jordan, Amman, 11942, Jordan

e-mail: h.alduraidi@ju.edu.jo

Phone: +962 65355000 Ext. 23169

Cell Phone: +962 772724079
As a result of political turmoil, destruction, and armed conflict, millions of Syrians have become refugees, faced with the reality of fleeing their previous lives, their homes, and sometimes, even members of their families. They have headed to other regions in Syria, or other countries in search of safety and protection ${ }^{[1]}$. Since the fighting in Syria began in 2011, more than 470, 000 people have been killed, 1 million injured, and several millions forced to flee their homes for fear of persecution and seek asylum elsewhere ${ }^{[1]}$. Syrian refugeesfled to neighboring nations such as Lebanon, 
Jordan, and Turkey in order to stay safe and salvage their lives and their family's lives ${ }^{[2]}$.

Jordan historically hosted several waves of refugees from neighboring countries, such as Palestine and Iraq ${ }^{[3]}$. Today, Jordan alone hosts over 680 thousand registered Syrian refugees, but this only represents a fraction of the total number of Syrian refugees in country, which is estimated to be 1.4 million, or $20 \%$ of Jordan's population ${ }^{[2]}$. The vast majority of Syrian refugee communities in Jordan (approximately $80 \%$ ) are located in non-camp settings, specifically in cities close to the Northern border between Jordan and Syria, including Mafraq and Irbid, and in the capital, Amman ${ }^{[4]}$. Over $85 \%$ of Syrian refugee population live under poverty line ${ }^{[4]}$.

The aforementioned circumstances make the daily life of Syrian refugees filled with hardships and stressors on the physical and social levels. Syrian refugees often live with limited means to provide shelter and food to their children and families, representing basic necessities of survival ${ }^{[5]}$. There is no question that Syrian refugees residing in Jordan face grave and often insurmountable financial barriers towards accessing basic health services, which leads to poor health ${ }^{[3]}$. Therefore, this paper investigates the socio-demographic predictors of Syrian refugees' perceived physical, psychological, social and environmental health.

\section{Materials and Method}

Design: A cross-sectional quantitative descriptive design was utilized to identify association between socio-demographic characteristics (such as gender, age group, place of living, family size, marital status, educational level, employment status and income level) as independent variables, and perceived physical, psychological, social and environmental health as dependent variables.

Settings: Sample was recruited from Syrian refugee communities inside Zaatari refugee camp, and in noncamp settings in greater Amman and Zarqaa.

Sample and Population: A sample of 151 registered Syrian refugees aged 18 years and above, willing to participate were included in this study. Those with terminal illnesses or severe disabilities were excluded.

Data collection Procedures: Data collection started after acquiring ethical approval from the Institutional
Review Board (IRB) Committee of the School of Nursing, The University of Jordan. Potential participants were approached in their communities between September and November 2019, merit of the study and its benefits were explained, informed consent was signed, and then the Arabic questionnaire was completed.

Instrument: The data was collected using a twopart questionnaire:

1. Socio-demographic data that include gender, age group, place of living, family size, marital status, educational level, employment status and income level.

2. A 12-item, Arabic, self-reported, perceived health questionnaire with four domains; perceived physical, psychological, social and environmental health. This questionnaire was developed by the authors in light of reviewing several international instruments. Face validity was confirmed by three experts.

Pilot Study: A pilot study on 22 subjects prior to the main study. Result showed satisfactory reliability with a Cronbach's alpha of .82 .

\section{Findings:}

Sample Characteristics: As presented in table (1), the sample consisted of 151 adult Syrian refugees whose ages ranged between 18 and 69 years, with a mean of 31.3 years $(\mathrm{SD}=10$ years). Age was recoded into three age groups for statistical purposes, as shown in the table. Majority (73.5\%) were males, and married $(54.3 \%), 31.8 \%$ were single, and those a few reported being widowed $(7.3 \%)$ or divorced $(6.6 \%)$. Ninety-one participants $(60.3 \%)$ resided outside camp in Amman or Zarqaa', and 60 participants (39.7\%) resided in AlAzraq refugee camp. In terms of educational level, 38 participants $(25.2 \%)$ reported receiving education lower than middle school, 20 participants $(13.2 \%)$ had middle school education, 70 participants $(46.4 \%)$ had high school education, and only 23 participants $(15.2 \%)$ had some college or university degree. Those who reported a monthly family income below absolute poverty line (at about JD200 per month per household) were only 7 $(7.3 \%)$, those who reported a family monthly income between absolute poverty line and poverty line (at about JD400 per month per household) were 36 (37.5\%), and those who reported a family monthly income above poverty line were $53(55.2 \%)$ (DOS, 2019). It is important to report that out of the 151 participants, 
55 decided not to answer the income question, so the numbers in the table add up to 96 participants.

Table 1. Sample Characteristics $(\mathrm{N}=151)$

\begin{tabular}{|l|c|}
\hline Characteristic & Count (\%) \\
\hline Gender Male & $111(73.5)$ \\
\hline Female & $40(26.5)$ \\
\hline Age Group 18-29 years & $73(48.3)$ \\
\hline 30-39 years & $54(35.8)$ \\
\hline 40 years or older & $24(15.9)$ \\
\hline Marital Status Single & $48(31.8)$ \\
\hline Married & $82(54.3)$ \\
\hline Widowed & $11(7.3)$ \\
\hline Divorced & $10(6.6)$ \\
\hline Living Place Inside Camp & $60(39.7)$ \\
\hline Outside Camp & $91(60.3)$ \\
\hline Educational Level Below Middle School & $38(25.2)$ \\
\hline Middle School & $20(13.2)$ \\
\hline High School & $70(46.4)$ \\
\hline College or Higher & $23(15.2)$ \\
\hline Employment Status Unemployed & $75(49.7)$ \\
\hline Employed & $76(50.3)$ \\
\hline Family Monthly Income Level* Below & $36(37.5)$ \\
\hline JD199 & $53(55.2)$ \\
\hline JD300 or Higher & $7.3)$ \\
\hline
\end{tabular}

*55 participants $(36.4 \%)$ chose not to answer this question

\section{Perceived Health Scores}

A 12-item, Arabic language questionnaire was used to test the perceived health score for each of the four domains; physical, psychological, social and environmental. Items of the questionnaire were Likerscale type ranging from extremely poor to extremely satisfying. Each domain's score was computed out of 60 .

The score for perceived physical health ranged between 4.5 and 56.9 , with a mean of $27.6 \pm 11.5$ out of 60 ; perceived psychological health scores ranged between 4 and 52.7 with a mean of $27.1 \pm 10.1$ out of 60 ; perceived social health scores ranged between 6.8 and 60 , with a mean of $32.6 \pm 10.3$ out of 60 ; and perceived environmental health scores ranged between 5.8 and 58.8 , with a mean of $30 \pm 9.1$ out of 60 .
Socio-demographic Predictors: The scores of each of the four domains of perceived health was tested for its association with socio-demographic characteristics. These characteristics included gender, age group, marital status, employment status, household size, educational level, income status, as well as living place (inside vs. outside camp). This association was tested using a series of independent-sample $t$ tests, one-way ANOVA tests, and Pearson's $\mathrm{r}$ correlation tests according to each variable type. A number of socio-demographic characteristics were found to be significantly associated with each of the four domains' scores, and are therefore considered predictors.

Socio-demographic predictors of perceived physical health included age group, where participants aged 1829 scored 31.3, those aged 30-39 scored 27.8, and those aged 40 or older scored only $24.4\left(\mathrm{~F}_{(2)}=3.12, \mathrm{p}=.012\right)$; marital status, where single participants scored 28.8, married scored 26.9, divorced scored 22.9, and widow/ er scored only $22\left(\mathrm{~F}_{(3)}=4.71, \mathrm{p}=.004\right)$; and income level, where participants whose families receive a monthly income below JD199 scored only 25.8, those between JD200-299 scored 27, and those above JD300 scored $30.1\left(\mathrm{~F}_{(2)}=1.75, \mathrm{p}=.047\right)$.

Socio-demographic predictors of perceived psychological health also included monthly income level,where participants whose families receive a monthly income below JD199 scored only 28, those between JD200-299 scored 29.2, and those above JD300 scored $31.4\left(\mathrm{~F}_{(2)}=2.79, \mathrm{p}=.005\right)$; place of living, where refugees inside camps scored 26.9, and those outside camps scored 29.6 $(\mathrm{t}=3.32, \mathrm{p}=.007)$; and marital status, where single participants scored 27.8, married scored 27.1, divorced scored 23.5, and widow/er scored only $22.9\left(\mathrm{~F}_{(3)}=4.09, \mathrm{p}=.034\right)$.

Socio-demographic predictors of perceived social health included gender, where males scored 32.6, and females scored $29.9(\mathrm{t}=2.04, \mathrm{p}=.026)$; age group, where participants aged 18-29 scored 33, those aged 30-39 scored 29.7, and those aged 40 or older scored only 26.2 $\left(\mathrm{F}_{(2)}=3.64, \mathrm{p}=.000\right)$; living place, where refugees living inside camps scored 32.6, and those living outside camps scored 27.3( $\mathrm{t}=-3.61, \mathrm{p}=.031)$, and household size, where a statistically-significant correlation was found between number of household members and perceived social health score (Pearson's $\mathrm{r}=.61, \mathrm{p}=.048$ ). 
Finally, the only socio-demographic predictor of perceived environmental health was place of living, where refugees living inside camps scored 29.6, and those living outside camps scored 33.7( $\mathrm{t}=5.64, \mathrm{p}=.000)$. All other socio-demographic characteristics were not significantly associated with the score of environmental health domain.

\section{Discussion}

Numerous research found a strong association between health and socio-demographic factors in several populations, namely among refugees ${ }^{[3]}$. Regarding living inside refugee camps, the findings of this study came in line with the results of a 2017 study by Alduraidi \& Waters, where Palestinian refugees inside refugee camps fared worse in terms of both physical and environmental health, but fared better in terms of social relationships ${ }^{[5]}$. The explanation of these findings may be the strong connections between refugee families inside the camp, and the shared concerns, hopes and stressors between these families.

Regarding the association between poverty and inferior physical health, a 2015 study by HamdanMansour and colleagues suggested that poverty predicted worse health and life satisfaction among Jordanian patients ${ }^{[6]}$. This association was also evident in a 2020 study by Alduraidi and colleagues, where Syrian refugees with lower financial resources demonstrated lower resilience than their younger counterparts ${ }^{[7]}$.

In terms of the association between age and perceived physical and psychological health, the findings of this study came in line with those of a 2017 study by Hamdan-Mansour and colleagues and a 2020 study by Khatib and colleagues, as well as a 2020 study by Alduraidi and colleagues ${ }^{[8-9-7]}$. It is worth mentioning that another 2017 study by Hamdan-Mansour and colleagues, and a 2019 study by Saleh and colleagues have revealed that the older the person, the more likely he/she is to express inferior physical health problems both subjectively and objectively ${ }^{[10-11]}$.

Furthermore, relatively-high numbers of divorced and widow individuals, and relatively large family size are characteristics of refugee communities as revealed in a 2018 study by Alduraidi \& Waters, where these socio-demographic characteristics were found to be significantly associated with distress, sadness, and poor perceived psychological health ${ }^{[3]}$.

\section{Conclusion}

The findings of this study provide an evidence that some modifiable socio-demographic characteristics are associated with inferior perceived health scores among Syrian refugees in Jordan. Poverty and large household size were associated with inferior perceived physical, psychological and social health. It is, therefore, recommended that policy makers should target resolving the problem of limited financial resources and large family size among Syrian refugees in Jordan.

Living inside refugee camp was associated with inferior perceived psychological and environmental health on one hand. On the other hand, perceived social health inside the camp was superior. Policy makers should, therefore, establish psychological/mental health services, and work on improving physical environmental conditions inside the camp. Meanwhile, policy makers should implement solutions for promoting social support networks among refugees outside the camp. Finally, older refugees, divorced and widow individuals expressed low scores in several domains. Thus, policy makers are invited to implement programs to help promote health in these special demographics.

Conflict of Interest: The authors declare no conflict of interest related to publication of this article.

Financial Disclosure: There is no financial disclosure.

Ethical Clearance: The study has been approved by the ethics and research committee at The school of Nursing, The University of Jordan.

\section{References}

1. Rizkalla, N., \& Segal, S. P. Well-Being and Posttraumatic Growth Among Syrian Refugees in Jordan. Journal of Traumatic Stress, 2018. 31(2), 213-222. https://doi.org/10.1002/jts.22281

2. United Nations High Commissioner for Refugees. External Statistical Report on Active Registered Syrians in Jordan; 2200. http://data.unhcr.org/ syrianrefugees/download.php?id=8714. Accessed June 2, 2020

3. Alduraidi H, Waters CM. Depression, Perceived Health, and Right-of-Return Hopefulness of Palestinian Refugees. J Nurs Scholarsh. 2018; 50(2):163-171. doi:10.1111/jnu.12363 
4. Government of Jordan, Fafo Institute for Applied International Studies. The living conditions of Syrian refugees in Jordan: Results from the 20172018 survey of Syrian refugees inside and outside camps. Retrieved March 13, 2019 from: https:// reliefweb.int/report/jordan/living-conditionssyrian-refugees-jordan-results-2017-2018-surveysyrian-refugees

5. Alduraidi H, Waters CM. Health-related quality of life of Palestinian refugees inside and outside camps in Jordan. Nurs Outlook. 2017;65(4):436443. doi:10.1016/j.outlook.2017.05.007

6. Hamdan-Mansour AM, Al Abeiat DD, Alzoghaibi IN, Ghannam BM, Hanouneh S I. Psychosocial and sociodemographic correlates of life satisfaction among patients diagnosed with cancer in Jordan. $\mathrm{J}$ Cancer Edu 2015; 30(1): 31-36.

7. Alduraidi H, Dardas LA, Price MM. Social Determinants of Resilience Among Syrian Refugees in Jordan. J PsychosocNurs Ment Health Serv. 2020;58(8):31-38. doi:10.3928/0098913420200624-04
8. Hamdan-Mansour A. Sociodemographic correlates of somatic symptoms of older persons in Jordan. Jordan Med J 2017; 51 (3): 119-130.

9. Khatib A, Hamdan- Mansour A, Ratrout H, Alenezi A, Chahien T. Testing the effectiveness of integrated elderly care model on quality of care and health outcomes among hospitalized elderlies in West Bank. Malaysia Journal of Public Health Medicine 2020; 20(1): 82-89.

10. Hamdan-Mansour A, Shehadeh J, Puskar K, ElHneiti M, M Haourani E. Investigating physical, psychological and social well-being of older persons in Jordan. Current Aging Science. 2017 Aug 1;10(3):217-23.

11. Saleh ZT, Lennie TA, Alhurani AS, Almansour IM, Alduraidi H, Moser DK. High Dietary Sodium Intake is Associated with Shorter Event-Free Survival in Patients with Heart Failure and Comorbid Diabetes [published online ahead of print, 2019 Nov 18]. Clin Nurs Res. 2019;1054773819888743. doi:10.1177/1054773819888743. 